\title{
Compact multifunctional source-meter system for characterisation of laboratory- scale solar cell devices
}

Corazza, Michael; Garcia-Valverde, Rafael; Dam, Henrik F.; Madsen, Morten V.; Hösel, Markus; Benatto, Gisele A. dos Reis; Beliatis, Michail J.; Pastorelli, Francesco; Veenstra, Sjoerd; Knelissen, Guus

Total number of authors:

20

Published in:

Measurement Science and Technology

Link to article, DOI:

10.1088/1361-6501/aafae4

Publication date:

2019

Document Version

Peer reviewed version

Link back to DTU Orbit

Citation (APA):

Corazza, M., Garcia-Valverde, R., Dam, H. F., Madsen, M. V., Hösel, M., Benatto, G. A. D. R., Beliatis, M. J., Pastorelli, F., Veenstra, S., Knelissen, G., Galagan, Y., Roesch, R., Faber, T., Hoppe, H., Berson, S., Manceau, M., Chaperon, M., Castro, F., Blakesley, J., \& Gevorgyan, S. A. (2019). Compact multifunctional source-meter system for characterisation of laboratory- scale solar cell devices. Measurement Science and Technology, 30(3), [035901]. https://doi.org/10.1088/1361-6501/aafae4

\section{General rights}

Copyright and moral rights for the publications made accessible in the public portal are retained by the authors and/or other copyright owners and it is a condition of accessing publications that users recognise and abide by the legal requirements associated with these rights.

- Users may download and print one copy of any publication from the public portal for the purpose of private study or research.

- You may not further distribute the material or use it for any profit-making activity or commercial gain

- You may freely distribute the URL identifying the publication in the public portal 
ACCEPTED MANUSCRIPT

\section{Compact multifunctional source-meter system for characterisation of lab scale solar cell devices}

To cite this article before publication: Michael Corazza et al 2018 Meas. Sci. Technol. in press https://doi.org/10.1088/1361-6501/aafae4

\section{Manuscript version: Accepted Manuscript}

Accepted Manuscript is "the version of the article accepted for publication including all changes made as a result of the peer review process, and which may also include the addition to the article by IOP Publishing of a header, an article ID, a cover sheet and/or an 'Accepted

Manuscript' watermark, but excluding any other editing, typesetting or other changes made by IOP Publishing and/or its licensors"

This Accepted Manuscript is @ 2018 IOP Publishing Ltd.

During the embargo period (the 12 month period from the publication of the Version of Record of this article), the Accepted Manuscript is fully protected by copyright and cannot be reused or reposted elsewhere.

As the Version of Record of this article is going to be / has been published on a subscription basis, this Accepted Manuscript is available for reuse under a CC BY-NC-ND 3.0 licence after the 12 month embargo period.

After the embargo period, everyone is permitted to use copy and redistribute this article for non-commercial purposes only, provided that they adhere to all the terms of the licence https://creativecommons.org/licences/by-nc-nd/3.0

Although reasonable endeavours have been taken to obtain all necessary permissions from third parties to include their copyrighted content within this article, their full citation and copyright line may not be present in this Accepted Manuscript version. Before using any content from this article, please refer to the Version of Record on IOPscience once published for full citation and copyright details, as permissions will likely be required. All third party content is fully copyright protected, unless specifically stated otherwise in the figure caption in the Version of Record.

View the article online for updates and enhancements. 


\title{
Compact multifunctional source-meter system for characterisation of lab scale solar cell devices
}

Michael Corazza, ${ }^{\text {a }}$ Rafael García-Valverde, ${ }^{a}$ Henrik F. Dam, ${ }^{a}$ Morten V. Madsen, ${ }^{\text {a } M a r k u s ~ H o ̈ s e l, ~}{ }^{\text {a }}$ Gisele a. dos Reis Benatto, ${ }^{a}$ Michail J. Beliatis, ${ }^{a}$ Francesco Pastorelli, ${ }^{a}$ Sjoerd Veenstra, ${ }^{b}$ Guus Knelissen, ${ }^{\mathrm{b}}$ Yulia Galagan, ${ }^{\mathrm{c}}$ Roland Roesch, ${ }^{\mathrm{d}}$ Tobias Faber, ${ }^{\mathrm{d}}$ Harald Hoppe, ${ }^{\mathrm{d}}$ Solenn Berson, ${ }^{\mathrm{e}}$ Matthieu Manceau, ${ }^{\mathrm{e}}$ Mélodie Chaperon, ${ }^{\mathrm{e}}$ Fernando Castro, ${ }^{\mathrm{f}}$ James Blakesley, ${ }^{\mathrm{f}}$ and Suren A. Gevorgyan ${ }^{\mathrm{a} *}$

${ }^{a}$ Department of Energy Conversion and Storage, Technical University of Denmark, Frederiksborgvej 399, 4000-Roskilde, Denmark

${ }^{b}$ Energy Research Centre of the Netherlands (ECN), P.O. Box 1, 1755 ZG Petten, The Netherlands

${ }^{c}$ Holst Centre - Solliance, High Tech Campus 21, 5656AE, Eindhoven, The Netherlands

${ }^{d}$ Center for Energy and Environmental Chemistry Jena (CEEC Jena), Philosophenweg 7a, 07743 Jena, Germany

e Université Grenoble Alpes, INES, F-73375 Le Bourget du Lac, France

CEA, LITEN, Department of Solar Technologies, F-73375 Le Bourget du Lac, France

${ }^{f}$ Materials Division, National Physical Laboratory, Hampton Road, TW11 OLW Teddington, UK

e-mail: surg@dtu.dk

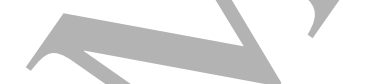

Keywords: characterisation, advanced sensors, Arduino, source meters, photovoltaics, R-Studio, environmental measurements, open source, graphical user interface, electrical circuitry

\begin{abstract}
The article presents an innovative and low cost solution for optimizing the acquisition of performance data of small laboratory scale photovoltaic devices. A novel measuring setup is proposed, designed based on an Arduino microcontroller and low cost components, coupled with open source hardware and software. The manuscript describes in detail the instrument design, components and assembly enabling the reproduction and customization of the instrument for any reader. The setup is combined with an optional web-platform, which enables fast analyses and comparison of the collected data.

For the demonstration of the instrument in operation, comparison of measurements of solar cell with the developed setup and commercial products has been conducted. It is shown that the presented prototype provides values of accuracy and precision during I-V curve recording, comparable with the values
\end{abstract}


measured using a commercial source-meter Keithley 2400. The study also discusses the unique advantages of easy transport and data collection by the setup and the drawbacks in the hardware, which have been observed during a round robin study.

\section{Introduction}

Characterisation instrumentation is a vital component in the process of developing advanced technologies, since characterisation helps understanding and improving the operational principles of various materials and devices. One of the important areas of research today is renewable energy and significant effort is put towards developing various technologies that can harvest renewable energy, such as solar cells, fuel cells, wind turbines and others. Among those, solar cells are one of the important technologies, which allow directly harvesting the solar energy from the sun. The biggest hurdle of the technology however remains the low efficiency of the devices and the most research is focusing towards improving the efficiency of these devices.

The race for developing the best new generation photovoltaic (PV) device continues, with the record photoconversion efficiencies (PCE) being periodically renewed for different technologies. The efficiency chart, published annually by NREL, provides the overview of the efficiency progress for all the solar cell types [1]. Some of the most intriguing classes that receive a lot of attention in recent years are the emerging photovoltaics [2]. These are typically based on organic materials (polymers [3-5], small molecules [6]), perovskites [7,8], dyes [9,10], CZTS [11,12] or quantum dots $[13,14]$. Common to all is that they need to go through a diligent laboratory research before reaching the commercialisation stage and the laboratory environment is where most of the device development and characterisation takes place initially.

The traditional and most common characterisation method for determining the conversion efficiency of a lab scale solar cell is measuring its volt-ampere characteristics (IV) by sweeping a voltage range and recording the current output from the sample. Doing such sweeps periodically allows also recording the lifetime or degradation patters in the performance of the sample along the time. Most laboratories typically utilise a combination of a source-meter, PC and a controlling software to run such IV measurement. Commercial source-meters are typically used for this purpose and as a standard, such source meters (for example Keithley 2400) are rather expensive and bulky. Especially bulkiness combined with the requirement of power socket, limit the applicability of such setups in remote outdoor 

portable and compact alternatives that can run on batteries could significantly ease IV recording process facilitating the PV research in the laboratory environments.

In addition, the aforementioned emerging PVs are typically much more sensitive towards environmental conditions than their inorganic counterparts [2] and therefore, often require a good control of the environmental parameters during IV testing [15], especially when tested for lifetime [16-18]. Examples are air and device temperature, humidity, light intensity and others. A small difference in testing conditions such as fluctuations in humidity, temperature or irradiance may lead to erroneous measurements [19,20]. Simultaneous recording of such parameters during IV testing would help eliminating the effect of such parameters on the outcome of the performance measurements.

In this manuscript, a prototype of an innovative low cost test setup for PV measurements is presented, called Multi Measurements Kit (MMkit), which is proposed as alternative to expensive commercial equipment. The uniqueness of the setup is embedded in its multifunctionality and low cost and to the best of our knowledge MMkit is the first in its kind. The setup is based on an open source hardware and software and it utilizes mainly inexpensive electronic components. MMkit has a compact structure and is designed to require minimal power consumption, which enables its easy transport and use in remote areas using batteries as power supply. More importantly, the setup contains integrated sensors for measuring certain environmental parameters, which provides several degrees of control and accuracy during tests. The concept of the MMkit is rather simple and is accessible for anyone having only a small budget. The hardware is based on an Arduino platform and ad-hoc shields to perform multiple functions. The new shield integrated in the MMkit allows running periodic IV sweeps for lab scale devices with current limited to $70 \mathrm{~mA}$ (for the presented prototype) and at the same time enables recording the environmental parameters using an additional board, which includes humidity, temperature and irradiance sensors. The specific code for the Arduino platform is briefly outlined as well. The setup can run in both manual and autonomous modes. For communicating with and interactively controlling the instrument, two software tools were developed: the graphical user interface (GUI) for accessing and controlling the instrument from a PC and a web-based data analysing tool for handling the collected data. For the autonomous mode, the measurement settings of the MMkit are pre-programmed via the GUI prior to the measurements and the setup then automatically performs the desired measurements and saves the recorded data onto integrated memory card without further control. In the manual mode, the setup is 
continuously controlled via GUI along the measurements. All the designs and software are open source and the links to all the resources are provided in this manuscript.

Although the setup is aimed at characterisation of solar cells, the presented approach and concepts, such as open source tools and low cost components can possibly be utilised in similar setups for characterising other types of printed electronics, such as fuel cells, OLEDs, transistors and other printed electronics.

\section{Description of experimental setup}

\subsection{Hardware}

Figure 1 shows a capture of the MMkit setup which consists of two main units: core unit and sensors unit. Figure 2 shows a flow diagram indicating the different functionalities embedded in the MMkit, while Table 1 reports the cost of the employed components with the total cost of the hardware amounting to approximately 80 US \$.

The core unit contains the main hardware, which is protected from the testing environment by a waterproof container (protection rate IP66). The core unit is equipped with an Arduino Mega 2560 and an Arduino Ethernet shield, which provides an SD card slot used to save the data locally and an Ethernet port that can be used to transfer the data directly over the internet (the latter function has not been utilized in this project) [21,22]. The collected data can also be transferred to a PC via a USB port. The core unit is equipped with a Real Time Clock (RTC) circuit, which is powered by a battery and is thus capable of maintaining the time reference also in offline mode. The integrated screen shows basic information regarding the operation of the setup, which is especially useful when the MMkit is being used without a PC (see free-mode in section 2.2.1). 


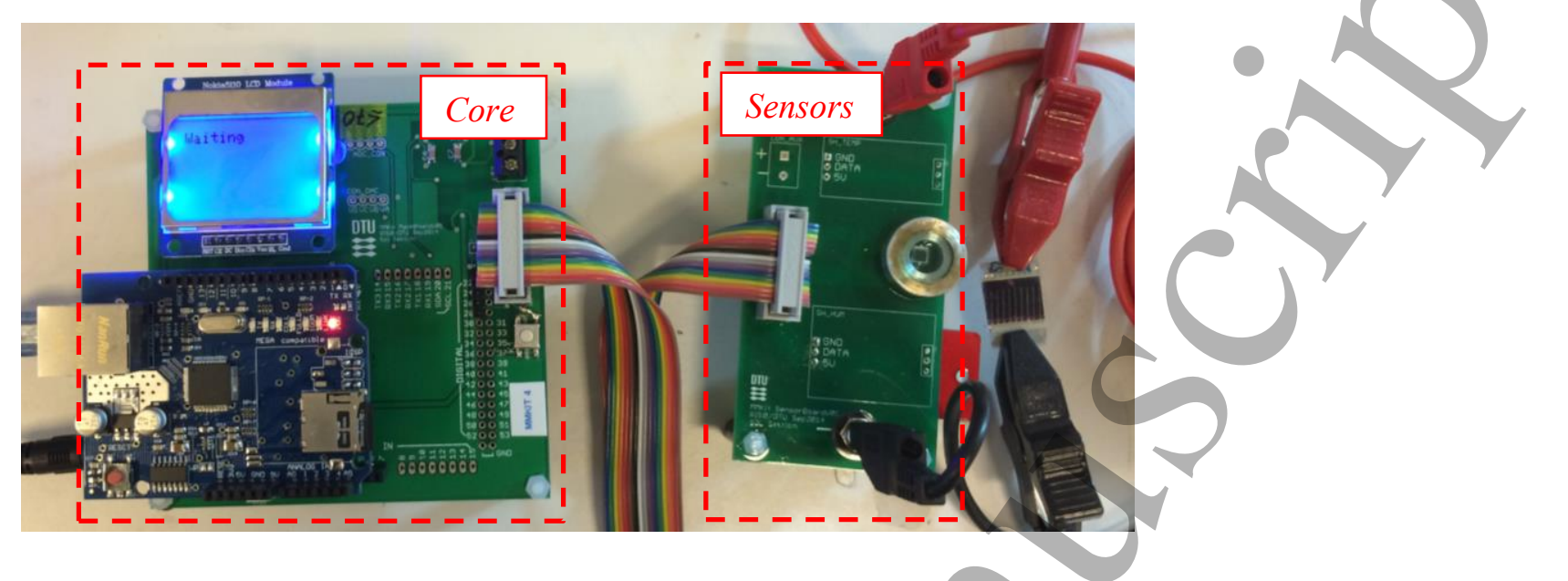

Figure 1. A picture of the MMkit core unit (left) and the sensors board (right). The two terminals of the test sample are connected to the sensors board (black and red cables). The core unit contains the developed shield for the IV curve tracer (in green), the Arduino Ethernet shield, the screen shield and on the bottom side (not visible) the RTC shield and the Arduino Board Mega 2560. On the sensors board a photodiode sensor is placed on the top side while the humidity and temperature sensors are placed on the other side (to protect from light exposure).

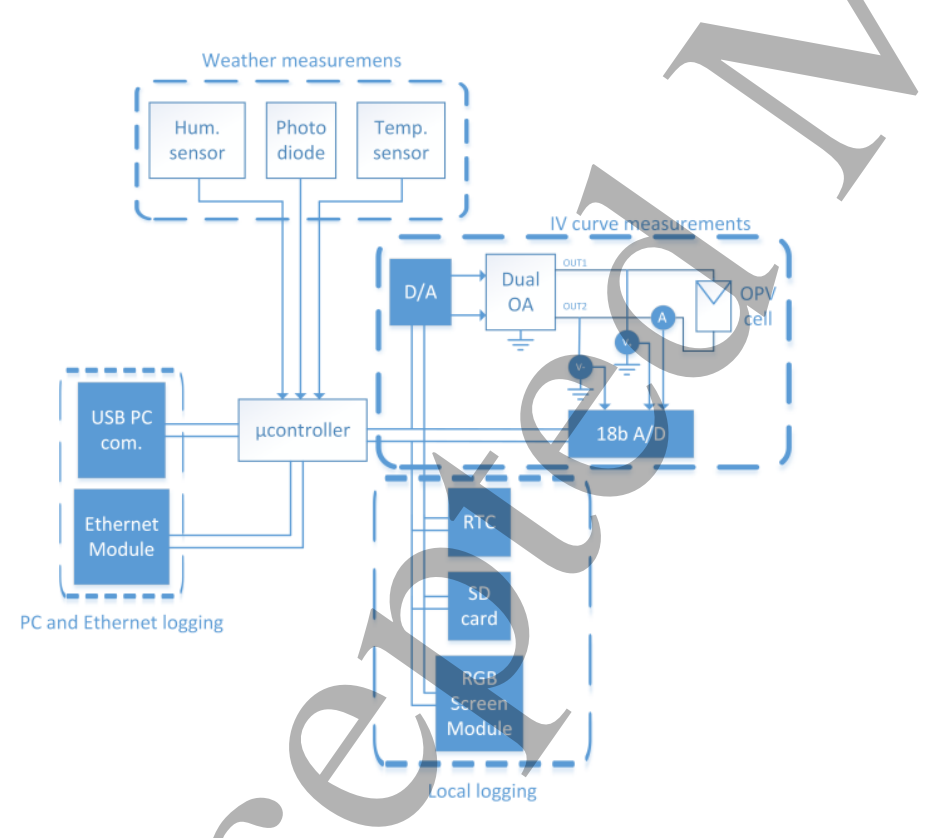

Figure 2. Flow diagram indicating the various functionalities of the MMkit.

The sensor unit includes the sensors responsible for the measurement of the environmental parameters, such as irradiance, humidity, and temperature. The system is rather versatile and can enable 
The core unit contains the hardware used for the measurement of the IV curves, which is based on the source-meter developed at MIT University [23]. The schematics of the IV curve circuit is shown in Figure 3. The basic idea is to apply a voltage sweep over the DUT terminals through an operational amplifier able to sink the maximum expected current from the DUT, using the amplifier as load and measuring the current and voltage during the sweep. Dual operational amplifier LM7332A from Texas Instruments (IC3A and IC3B on the schematic) has been used for this purpose, which can be supplied by up to $32 \mathrm{~V}$ and sink up to $70 \mathrm{~mA}$. In the case the solar cell is expected to exceed such limits during the test, the operational amplifier should be substituted with a compatible one. Each amplifier output builds a voltage, referenced from the ground (GND). Therefore, the differential voltage applied to the DUT can 
be swept in a range from $-12 \mathrm{~V}$ to $12 \mathrm{~V}$ (limited by the $12 \mathrm{~V}$ supplied by the Arduino). Previous low cost IV tracers [24,25] based on the use of a simple capacitive load were limited to only positive voltage sweeps.

The voltage applied during the voltage sweep is controlled digitally from the microcontroller through the $\mathrm{I}^{2} \mathrm{C}$ protocol using the two digital lines SCL and SDA (see Figure 3). The Digital-Analog converter, (MCP4728 from Microchip) receives the voltage references to be applied to the Dual Amplifier and converts it to an analogue value, which is amplified by the operational amplifiers (IC3A and IC3B). The Analog-Digital converter MCP3424 digitalizes both the current and the voltage measurements.

A shunt resistance (Rs) is used to measure the current flowing in the DUT. The measurement is done by amplifying the proportional voltage dropping across the shunt resistance and by converting it into current using Ohm's law. Since the measurement unit is in parallel to the resistance, the resistance is called shunt, although it is in serial connection with the load. It is a two-terminal resistor with high accuracy ( $<=1 \%$ tolerance) and very low resistance value to minimize any effect on the DUT. The shunt resistor value can be tuned, but since the MCP3424 (the ADC) can scale the GAIN dynamically, we recommend using a small value for the shunt-resistor (Rs). Since the DUT terminals are not referenced to GND, the current must be measured in an isolated way. Therefore, the differential isolated amplifier AMC1200 from Texas Instruments has been utilized to amplify the voltage drop in the shunt resistance. Note that the isolated side (5V_ISO and GND_ISO in Figure 3) of the amplifier must be supplied from an isolated DC/DC supplier, for instance IK0505SA from XP Power. The rest of the components are supplied directly from the Arduino board, either from the $12 \mathrm{~V}$ input (Dual operational amplifier) or from the $5 \mathrm{~V}$ line (rest of integrated circuits). It was found useful to include the measurements of the applied voltage in order to have a feedback information and get better accuracy during the voltage sweep (PV_POS and PV_NEG in the schematics). 


\subsection{Software}

\subsubsection{Arduino code}

Figure 3. Simplified schematics of the I-V curve measurement circuit.

The code developed for Arduino uses several open source libraries developed by the Arduino community. All the software based on an open source and is freely available for download on the platform BitBucket [26]. The code is divided into a high-level management of the MMkit operational modes, and a low-level management of its basic functionalities. The high-level has to manage the two possible working modes of the MMkit, namely the PC-mode and the free-mode (to be explained below), while the low-level has to be able to read from the sensors and to measure the I-V curves.

The high-level code for the $P C$-mode contains a set of actions that the MMkit is capable of performing upon request of a specific command coming from the MMkit graphical user interface (GUI) via serial port (see section 2.2.2). In the free-mode, the MMkit is running autonomously based on preprogrammed commands, without further intervention of a PC. This mode is especially useful for outdoor lifetime studies, since the MMkit is water-proof and can be placed outdoor for long term studies without the support of a PC. In the free-mode, the MMkit runs following the settings stored in the SD-card, which can be setup using the MMkit GUI (see section 2.2.2). 


\subsubsection{Graphical User Interface (GUI)}

Using the console of the Arduino Development Kit it is possible to control the MMkit using the commands specified in the Table S1 in the supporting document. The commands listed in Table S1 are the same codes sent by the MMkit GUI via serial port to the MMkit when the user presses a button of the interface to communicate with the tool. The interested user can find the full list of the commands on the "PC_mode" section of the software contained in the MMkit Core folder, in the BitBucket repository referenced above.

The graphical user interface of the MMkit has been developed using Processing, an open source development environment based on Java. Such an environment allows developing multi-platform software, compatible with Mac OS X, Windows and Linux. Figure 4 shows the interface of the GUI. The upper-left part is used to connect the computer to the serial port used by the Arduino. Once the connection is established, the user can communicate with the MMkit. The area below the setting for the connection is used for selecting the parameters of the measurements, which are grouped into: "IV settings", "options", "interval between measurements", "update settings and plot options", "calibration", and "email report". The "IV settings" tab is used to choose the parameters that affect the sweep of the I-V curve: the user can choose the "start" and "stop" voltage, and the "number of data points" to acquire along the sweep. The option "number of meâsurements" allows performing stability studies, since the setup can repeatedly conduct measurements with an interval specified in the tab "interval between measurements". In the "options" tab, the user can activate the measurement of humidity, temperature, and the irradiance. If the irradiance is not measured, then the user can specify a default irradiance value in order to normalise the recorded pv parameters (device photocurrent and PCE). The field "area" is designated for defining the active area of the test device and must also be filled in order to calculate photocurrent density and the PCE of the measured sample. The option "auto save" is used to save automatically every measured data point. The data is saved in the folder chosen under the tab "choose folder". The button "Save data" is used to save a specific I-V curve, when the "auto save" mode is not activated. In order to save a specific I-V curve, the text box "n. IV" below the save data button can be

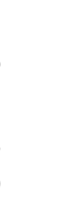


used to choose a specific I-V curve using the same number displayed in the legend of the I-V curve graph. The user can also specify any "note" regarding the ongoing test to be saved in the data file.

The MMkit GUI can save data both in a $c s v$ format and in a $t x t$ format. The specified filename identifies the root name of the generated files, to which a suffix is added. The file having the suffix summary contains the summary of the parameters extracted from each I-V measurement: PCE, short circuit current $\left(\mathrm{I}_{\mathrm{SC}}\right)$, open circuit voltage $\left(\mathrm{V}_{\mathrm{OC}}\right)$, fill factor $(\mathrm{FF})$, maximum power point ( $\left.\mathrm{P}_{\max }\right)$, humidity, temperature, and irradiance. The file with the suffix $i v$ contains all the parameters recorded in the summary and the complete I-V curve data. The generated $t x t$ file is used to upload the data directly onto an online database, discussed in Section 2.2.3, where the data becomes available for analysis in real time through an online tool.

The tab "update settings and plot options" is used to transfer the settings displayed in the MMkit GUI into the MMkit core. This step allows "to program" the MMkit to run autonomously without the need of a computer using the setting specified in the MMkit GUI (Free mode).

The "calibration" tab contains a tool that allows automatically calibrating the time of the RTC with the time of the PC. The "calibration" tab also allows specifying a calibration number that is used by the photodiode to convert its readings into irradiance. The tab "email report" is used to send automatically an email with a summary of the tests to a defined email address as soon as the device has gone below an arbitrary value of PCE, which can be specified by the user. This function is not fully implemented in the public version uploaded on the BitBucket repository, since the credentials used to send the email could not be made public. In the lower section of the GUI there are five graphs monitoring the measurements. The graphs show the PCE (calculated from the measured I-V curves), temperature, humidity and irradiance, all plotted against the elapsed time and the largest plot in the middle shows the last measured five I-V curves. 


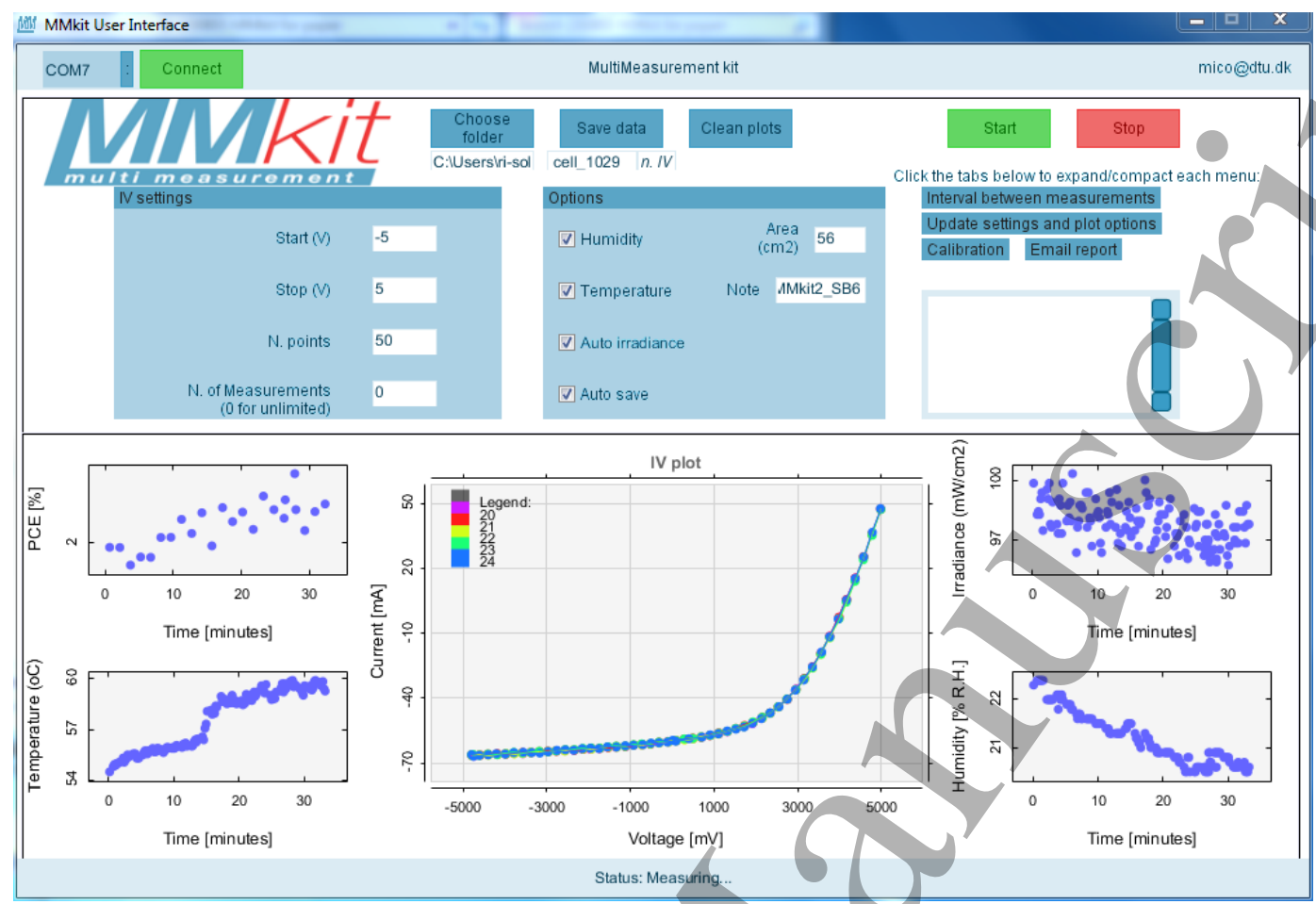

Figure 4. An example of a stability test monitored using the graphical user interface of the MMkit.

\subsubsection{Web-based data analysis tool}

For handling and visualising the data, collected by the MMkit a web-based platform was developed, hosted at http://plasticphotovoltaics.org. The concept is that after MMkit collects and saves the data in files, the files can be uploaded on a MySQL database via the online platform. The platform then allows producing and interactively altering the plots of the data via a range of filters and criteria in order to investigate and compare the data. To access the online platform login credentials are required and the interested reader can gain the access by contacting the authors of the paper and obtaining login credentials and instructions. Meanwhile, in Figure S1 in the supporting document the screenshot of the data-handling tool and the different filter tabs is presented. The tool was developed with $R$ programme and the package Shiny, developed by RStudio [27]. The filtering of the plots is done in real time on a dedicated Shiny Server, based on Linux Ubuntu. The tools allows plotting the different parameters, such as humidity, temperature, irradiance, $\mathrm{V}_{\mathrm{OC}}, \mathrm{I}_{\mathrm{SC}}, \mathrm{P}_{\max }$, or FF versus the time of measurements. Any of those parameters can also be distinguished by the colour, size and shape of the data labels. Data of several users, instruments of samples can also be compared to each other. 


\section{Results and Discussion}

The MMkit I-V curve tracer uses an external A/D converter (MCP3424) where each of itś differential inputs can be configured to use 18 bits for the conversion, leading to a resolution of $12, \mathrm{~V} / 2^{18}=46 \mu \mathrm{V}$. Therefore, the accuracy errors are related to the quality and tolerance of the analogue circuitry, i.e. resistances and operational amplifiers. There is always a design compromise between increasing the accuracy and keeping the low cost for circuitry. In this prototype, using passive components with a tolerance of $1 \%$ and avoiding operation close to rail conditions in the operational amplifiers, accuracy and precision can be maintained at acceptable levels for our goals.

To demonstrate the accuracy of the instrument, MMkit performance was compared to an advanced commercial digital multimeter, Keithley 2400 (having a cost of more than an order of magnitude higher than the MMkit). Several voltage sweeps were performed on the same solar cell using both MMkit and Keithley. Examples of two I-V curves measured by MMkit and Keithley are shown in Figure 5 presenting a very good match. Table 2 shows the statistical comparison of the two setups based on eight I-V measurements. The average values (AVG), standard deviation (SD) and coefficient of variation (CV the ratio of the SD to the mean) are calculated based on eight I-Vs. The precision (repeatability of measurements) of the instruments was determined from the SD and CV, while the accuracy of MMkit was estimated from the AVG value by taking the Keithley AVG values as the baseline. The calculations were done for the four PV parameters: efficiency (PCE), open circuit voltage $\left(\mathrm{V}_{\mathrm{OC}}\right)$, short circuit current (ISC) and fill factor (FF). From the table, it is evident that the precision of Keithley is better for all the PV parameters, as can be seen from the SD and CV values (as expected for a tool costing one order of magnitude more). Nevertheless, the precision of the MMkit is also very high with a CV always below 2 $\%$. Moreover, the accuracy of the MMkit proved to be rather high, showing only $4 \%$ deviation from Keithley at most. There is no need for higher precision and accuracy when periodic characterisation of solar cells in research lab environment is in question, unless reporting of record efficiency is needed, in which case a certification of the device performance by an a accredited laboratory would anyway be required. Important to also note, that the simultaneous recording of the environmental parameters allows taking into account their effect on the result, which otherwise would not be possible if even high precision instruments would be used. Thus, the presented prototype provides a number of important advantages 
such as compactness, easy transport, remote use, recording of environmental parameters and low cost with acceptable compromise in the accuracy of measured data.

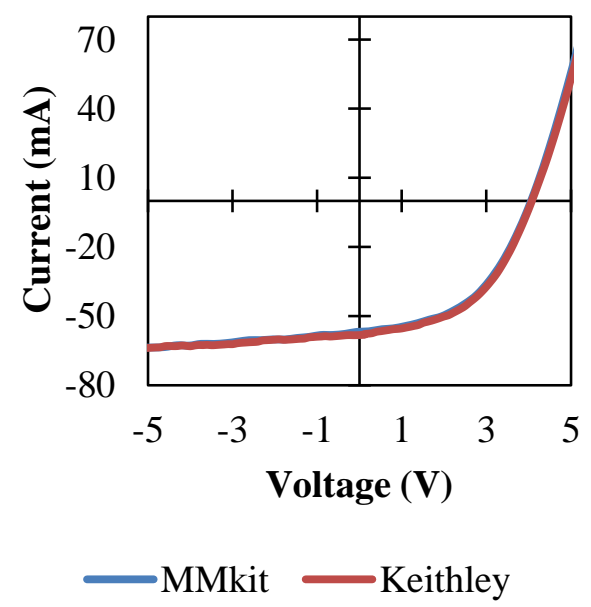

Figure 5. Comparison of I-V curves measured with Keithley 2400 and MMkit. Keithley was set to work in the sensitivity range of $100 \mathrm{~mA}$ acquiring 1 data point every $100 \mathrm{mV}$ with a total sweep time of 10 seconds, while the MMkit acquired 1 data point every $200 \mathrm{mV}$ with a total sweep time of 17 seconds.

Table 2. Summary of the measured values of PV parameters (PCE, $\mathrm{V}_{\mathrm{OC}}, \mathrm{I}_{\mathrm{SC}}, \mathrm{FF}$ ) and statistical indicators (standard deviation $-\mathrm{SD}$, coefficient of variation $-\mathrm{CV}$, and accuracy) used to confirm precision and accuracy of the MMkit $\mathrm{I}-\mathrm{V}$ curve tester.

\begin{tabular}{|lcccc|}
\hline & $\begin{array}{c}\text { PCE } \\
(\boldsymbol{\%})\end{array}$ & $\begin{array}{c}\text { Voc } \\
(\mathbf{m V})\end{array}$ & $\begin{array}{c}\text { Isc } \\
(\mathbf{m A})\end{array}$ & $\begin{array}{c}\text { FF } \\
(\boldsymbol{\%})\end{array}$ \\
\hline Keithley AVG & 1.00 & 505 & 4.26 & 46.3 \\
Keithley SD & 0.01 & 0.15 & 0.02 & 0.43 \\
Keithley CV (\%) & 0.65 & 0.03 & 0.39 & 0.93 \\
MMkit AVG & $1.04)$ & 511 & 4.35 & 46.7 \\
MMkit SD & 0.02 & 0.69 & 0.04 & 0.65 \\
MMkit CV (\%) & 1.45 & 0.13 & 0.96 & 1.40 \\
MMkit Accuracy*(\%) & 4 & 1 & 2 & $<1$ \\
*MMkit accuracy is defined as the percent of deviation of AVG value from Keithley AVG
\end{tabular}

To test the MMkit in real life, it was sent around to five laboratories (ECN - NL, TNO - NL, CEEC Jena - DE, CEA - FR, NPL - UK), where lifetime measurements of organic solar cells under indoor or 
outdoor conditions were conducted according to ISOS testing standards [28] using the MMkit. For this purpose, four MMkits were distributed among the laboratories. The results of the measurements at the different laboratories were then collected and analysed on the online platform by DTU. Such round robin study demonstrated the important advantage of the compactness of the MMkit, which enabled easy sharing of the system with others and comparing the measurements of devices at different locations. The detailed analyses of the results are not within the scope of this paper. However, it is useful to mention that we came across several pitfalls related to the setup during the studies. In particular, malfunctioning of some of the sensors or the screen of the setup was reported by certain labs. The reason behind such failures was often the loose contact and therefore, extra care is necessary to assure proper connection of all the parts and a good sealing of the setup. Currently, the second version of the setup is being developed, which will address all the failures identified for the first prototype.

Overall, the studies proved the unique advantages of the proposed setup and data-handling methods, which can be achieved having significantly lower budget than what is required today for obtaining wellestablished commercial products. It is therefore our hope that this manuscript will help the community in building and utilising such setups, which will eventually help improving the solar cell characterisation process and will aid the development of competitive technologies.

\section{Conclusions}

A low cost multi-functional setup for conducting characterization of lab scale solar cells was presented, which is solely based on open source tools and low-cost components. The hardware and the software were described in detail and the operational principles were outlined. The setup allows monitoring several environmental parameters (temperature, humidity, and irradiance) in parallel to I-V recording. In addition, due to its compactness and low power consumption the setup enables easy transport and conducting of measurements in remote areas, as it can run on batteries. Moreover, the overall cost of the presented prototype does not exceed 80 US dollars. The setup is supported by an optional online data-handling platform, which enables data collection on MySQL server, data analysing and visualisation of the data via a visualisation tool (based on Shiny package of R-Studio). However, any user with light programming skills can easily develop a customised code or use Excel for handling the data. 


\section{References}

[1] National Renewable Energy Laboratory (NREL), Efficiency chart, (2018). https://www.nrel.gov/pv/assets/pdfs/pv-efficiencies-07-17-2018.pdf (accessed September 5, 2018).

[2] J. Jean, P.R. Brown, R.L. Jaffe, T. Buonassisi, V. Bulović, Pathways for solar photovoltaics, Energy Environ. Sci. 8 (2015) 1200-1219. doi:10.1039/C4EE04073B.

[3] S. Gu, H. Neugebauer, N.S. Sariciftci, Conjugated Polymer-Based Organic Solar Cells, Chem.Rev. (2007) 1324-1338. doi:10.1021/cr050149z.

[4] H. Spanggaard, F.C. Krebs, A brief history of the development of organic and polymeric photovoltaics, Sol. Energy Mater. Sol. Cells. 83 (2004) 125-146. 
doi:10.1016/j.solmat.2004.02.021.

[5] G. Dennler, M.C. Scharber, C.J. Brabec, S. Gowrisanker, J.J.M. Halls, D. Laird, S. Jia, S.P. Williams, Polymer-fullerene bulk-heterojunction solar cells, Adv. Mater. 22 (2009) 3839-3856. doi:10.1002/adma.200801283.

[6] M. Riede, T. Mueller, W. Tress, R. Schueppel, K. Leo, Small-molecule solar cells — status and perspectives, Nanotechnology. 19 (2008) 424001. doi:10.1088/0957-4484/19/42/424001.

[7] M.K. Assadi, S. Bakhoda, R. Saidur, H. Hanaei, Recent progress in perovskite solar cells, Renew. Sustain. Energy Rev. 81 (2018) 2812-2822. doi:10.1016/j.rser.2017.06.088.

[8] S. Yang, W. Fu, Z. Zhang, H. Chen, C.-Z. Li, Recent advances in perovskite solar cells: efficiency, stability and lead-free perovskite, J. Mater. Chem. A. 5 (2017) 11462-11482. doi:10.1039/C7TA00366H.

[9] B. O'Regan, M. Grätzel, A low-cost, high-efficiency solar cell based on dye-sensitized colloidal TiO2 films, Nature. 353 (1991) 737-740. doi:10.1038/353737a0.

[10] M. Ye, X. Wen, M. Wang, J. Iocozzia, N. Zhang, C. Lin, Z. Lin, Recent advances in dyesensitized solar cells: from photoanodes, sensitizers and electrolytes to counter electrodes, Mater. Today. 18 (2015) 155-162. doi:10.1016/j.mattod.2014.09.001.

[11] T.K. Todorov, J. Tang, S. Bag, O. Gunawan, T. Gokmen, Y. Zhu, D.B. Mitzi, Beyond 11\% Efficiency: Characteristics of State-of-the-Art Cu $2 \mathrm{ZnSn}(\mathrm{S}, \mathrm{Se}) 4$ Solar Cells, Adv. Energy Mater. 3 (2013) 34-38. doi:10.1002/aenm.201200348.

[12] H. Katagiri, K. Jimbo, W.S. Maw, K. Oishi, M. Yamazaki, H. Araki, A. Takeuchi, Development of CZTS-based thin film solar cells, Thin Solid Films. 517 (2009) 2455-2460. doi:10.1016/j.tsf.2008.11.002.

[13] J. Albero, J.N. Clifford, E. Palomares, Quantum dot based molecular solar cells, Coord. Chem. Rev. 263-264(2014) 53-64. doi:10.1016/j.ccr.2013.07.005.

[14] M. Kouhnavard, S. Ikeda, N.A. Ludin, N.B. Ahmad Khairudin, B.V. Ghaffari, M.A. Mat-Teridi, M.A. Ibrahim, S. Sepeai, K. Sopian, A review of semiconductor materials as sensitizers for quantum dot-sensitized solar cells, Renew. Sustain. Energy Rev. 37 (2014) 397-407. doi:10.1016/j.rser.2014.05.023.

[15] F.C. Krebs, S.A. Gevorgyan, B. Gholamkhass, S. Holdcroft, C. Schlenker, M.E. Thompson, B.C. Thompson, D. Olson, D.S. Ginley, S.E. Shaheen, H.N. Alshareef, J.W. Murphy, W.J. 
Youngblood, N.C. Heston, J.R. Reynolds, S. Jia, D. Laird, S.M. Tuladhar, J.G. a Dane, P. Atienzar, J. Nelson, J.M. Kroon, M.M. Wienk, R. a J. Janssen, K. Tvingstedt, F. Zhang, M. Andersson, O. Inganäs, M. Lira-Cantu, R. de Bettignies, S. Guillerez, T. Aernouts, D. Cheyns, L. Lutsen, B. Zimmermann, U. Würfel, M. Niggemann, H.F. Schleiermacher, P. Liska, M. Grätzel, P. Lianos, E. a. Katz, W. Lohwasser, B. Jannon, A round robin study of flexible largearea roll-to-roll processed polymer solar cell modules, Sol. Energy Mater. Sòl. Cells. 93 (2009) 1968-1977. doi:10.1016/j.solmat.2009.07.015.

[16] S.A. Gevorgyan, I.M. Heckler, E. Bundgaard, M. Corazza, M. Hösel, R.R. Søndergaard, G.A. dos Reis Benatto, M. Jørgensen, F.C. Krebs, Improving, characterizing and predicting the lifetime of organic photovoltaics, J. Phys. D. Appl. Phys. 50 (2017) 103001. doi:10.1088/13616463/50/10/103001.

[17] W.R. Mateker, M.D. McGehee, Progress in Understanding Degradation Mechanisms and Improving Stability in Organic Photovoltaics, Adv. Mater. 29 (2017) 1603940. doi:10.1002/adma.201603940.

[18] P. Cheng, X. Zhan, Stability of organic solar cells: challenges and strategies, Chem. Soc. Rev. 45 (2016) 2544-2582. doi:10.1039/C5CS00593K.

[19] S.A. Gevorgyan, A.J. Medford, E. Bundgaard, S.B. Sapkota, H.F. Schleiermacher, B. Zimmermann, U. Würfel, A. Chafiq, M. Lira-Cantu, T. Swonke, M. Wagner, C.J. Brabec, O. Haillant, E. Voroshazi, T. Aernouts, R. Steim, J. a. Hauch, A. Elschner, M. Pannone, M. Xiao, A. Langzettel, D. Laird, M.T, Lloyd, T. Rath, E. Maier, G. Trimmel, M. Hermenau, T. Menke, K. Leo, R. Rösch, M. Seeland, H. Hoppe, T.J. Nagle, K.B. Burke, C.J. Fell, D. Vak, T.B. Singh, S.E. Watkins, Y. Gạlagan, A. Manor, E. a. Katz, T. Kim, K. Kim, P.M. Sommeling, W.J.H. Verhees, S.C. Veenstra, M. Riede, M. Greyson Christoforo, T. Currier, V. Shrotriya, G. Schwartz, F.C. Krebs, An inter-laboratory stability study of roll-to-roll coated flexible polymer solar modules, Sol. Energy Mater. Sol. Cells. 95 (2011) 1398-1416. doi:10.1016/j.solmat.2011.01.010.

[20] S.A. Gevorgyan, M. V Madsen, H.F. Dam, M. Jørgensen, C.J. Fell, K.F. Anderson, B.C. Duck, A. Mescheloff, E.A. Katz, A. Elschner, R. Roesch, H. Hoppe, M. Hermenau, M. Riede, F.C. Krebs, Interlaboratory outdoor stability studies of flexible roll-to-roll coated organic photovoltaic modules: Stability over 10,000h, Sol. Energy Mater. Sol. Cells. 116 (2013) 187- 
196. doi:10.1016/j.solmat.2013.04.024.

[21] Arduino, Getting Started with Arduino and Genuino MEGA2560, (2018). https://www.arduino.cc/en/Guide/ArduinoMega2560 (accessed September 6, 2018).

[22] Arduino, Getting Started with the Arduino Ethernet Shield, (2018). https://www.arduino.cc/en/Guide/ArduinoEthernetShield (accessed September 6,2018).

[23] MIT Photovoltaic Research Laboratory, Build Your Own Sourcemeter, (2018). http://pv.mit.edu/home/education/resources-for-educators/build-your-own-sourcemeter/ (accessed September 6, 2018).

[24] J.V. Muñoz, J. de la Casa Higueras, M. Fuentes, J. Aguilera Tejero, New Portable Capacitive Load Able to Measure PV Modules, PV Strings and Large PV Generators, in: Large PV Power Plants Distrib. PV Syst. Asp. Grid Connect., 26th EUPVSEC, n.d.: pp. 4276-4280. doi:10.4229/26thEUPVSEC2011-5BV.2.23.

[25] F. Spertino, J. Ahmad, A. Ciocia, P. Di Leo, A.F. Murtaza, M. Chiaberge, Capacitor charging method for I-V curve tracer and MPPT in photovoltaic systems, Sol. Energy. 119 (2015) 461473. doi:10.1016/j.solener.2015.06.032.

[26] M. Corazza, Bitbucket, (2018). doi:https://bitbucket.org/corazzam/mmkit/downloads/.

[27] RStudio, Shiny, (2018). http://shiny.rstudio.com/ (accessed September 6, 2018).

[28] M.O. Reese, S.A. Gevorgyan, M. Jørgensen, E. Bundgaard, S.R. Kurtz, D.S. Ginley, D.C. Olson, M.T. Lloyd, P. Morvillo, E. a. Katz, A. Elschner, O. Haillant, T.R. Currier, V. Shrotriya, M. Hermenau, M. Riede, K.R. Kirov, G. Trimmel, T. Rath, O. Inganäs, F. Zhang, M. Andersson, K. Tvingstedt, M. Lira-Cantu, D. Laird, C. McGuiness, S. Gowrisanker, M. Pannone, M. Xiao, J. Hauch, R. Steim, D.M. Delongchamp, R. Rösch, H. Hoppe, N. Espinosa, A. Urbina, G. Yaman-Uzunoglu, J.B. Bonekamp, A.J.J.M. Van Breemen, C. Girotto, E. Voroshazi, F.C. Krebs, Consensus stability testing protocols for organic photovoltaic materials and devices, Sol. Energy Mater. Sol.Cells. 95 (2011) 1253-1267. doi:10.1016/j.solmat.2011.01.036. 